
About IJMA [last updated July, $\left.1^{\text {st }}, 2021\right]$

$\checkmark$ International Journal of Medical Arts is the Official Journal of the Damietta Faculty of Medicine, AlAzhar University, Egypt

$\checkmark$ It is an International, Open Access, Double-blind, Peer-reviewed Journal

$\checkmark$ Published four times a year

$\checkmark$ The First Issue was published in July 2019

$\checkmark$ Published under the following license: Creative Commons Attribution-ShareAlike 4.0 International Public License (CC BY-SA 4.0). It had updated from the Creative Commons license [CC BY] in volume 2, Issue 4, October 2020 About IJMA

$\checkmark$ The Egyptian Knowledge Bank hosts the web site of IJMA

$\checkmark$ The Egyptian Knowledge Bank supports IJMA

$\checkmark$ IJMA follows the regulations of the International Committee of Medical Journal Editors

$\checkmark$ IJMA is indexed in the "Directory of Open Access Journals" [15 January 2021].

$\checkmark$ IJMA is indexed in JGate [29-6-2021]

$\checkmark$ IJMA is a member of the International Society of Managing and Technical Editors

$\checkmark$ Listed in "Index Copernicus", "Publons", "Academic resource index [ResearchBib]", "Electronics journal library", "Eurasian Scientific Journal Index", and "Citefactor"

$\checkmark$ IJMA introduced to the search engine [BASE] through DOAJ
Click image to reach the page

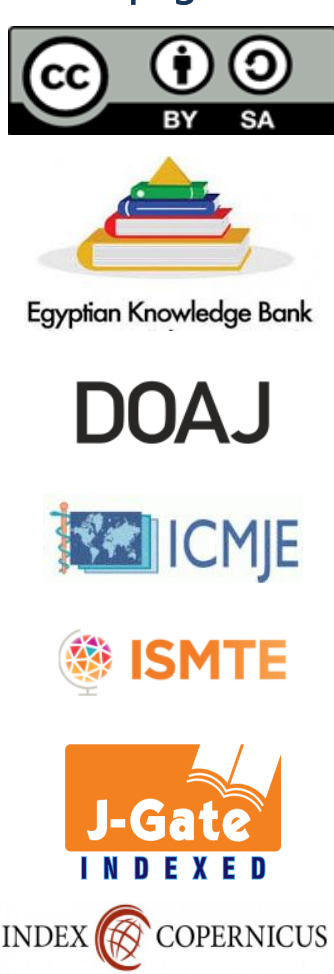

publons

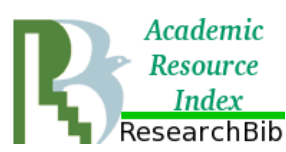

\section{EZ3 \\ .}

ESJII

CiteFactor

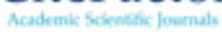

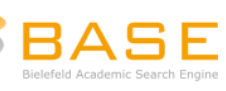




Available online at Journal Website
https://ijma.journals.ekb.eg/
Main subject [General Surgery]

Original article

\title{
Comparison between Single Mesh and Double Mesh Placement in Huge Inguinal Hernia
}

\author{
Ahmed Talat Ali Behiery [1]; Ahmed Salama Sayouh [2]; Nagah Atwa Salem [2] \\ 1 Department of Surgery, Ministry of Health, Egypt. \\ 2 Department of General Surgery, Damietta Faculty of Medicine, Al-Azhar University, Egypt. \\ Corresponding author: Ahmed Talat Ali Behiery \\ Email:ahmed.talaat@domazhermedicine.edu.eg
}

Submission date: January 04, 2021; Revision date: May 19, 2021; Acceptance date: May 28, 2021.

\section{ABSTRACT}

Background: Recurrence after surgical treatment of inguinal hernia is still a challenge facing surgeons during their daily practice.

Aim of the Work: The current trial aims to compare single and double mesh placement in huge inguinal hernia repair.

Patients and Methods: 40 cases were involved in the study. They were classified into two equal groups according to the operative technique [A for single mesh and B for double mesh]. The study's candidates were examined and investigated thoroughly regarding their complaint, the presence of a clinically detectable hernia in the inguinal region, its size, characters, onset, duration, and associated symptoms. Then, all were examined clinically and prepared for surgical intervention after lab investigations.

Results: The mean ages were 56 and 56.9 years for groups A and B. Both groups were comparable to body mass index, risk factors, type of hernia, hernia side, and intraoperative blood loss. There was a significant decrease in operative time in group A when compared to group $B$ [ $54.50 \pm 8.256$ vs. $61.25 \pm 6.664$ minutes, respectively]. The overall rate of complications was lower in group B when compared to group $A[30.0 \%$ vs. $50.0 \%$, respectively]. Complications in group A were seroma [10.0\%], wound infection [5.0\%], scrotal edema [25.0\%], and chronic pain [10.0\%]; while in group B, seroma [10.0\%], scrotal edema [5.0\%], chronic pain [15.0\%]. Recurrence was confined to group $A$, and reported to three patients [15.0\%]. However, the difference was statistically nonsignificant.

Conclusion: Double mesh technique is a safe and efficacious approach for managing huge inguinal hernia. It is associated with lower rate of recurrence than the single mesh approach with comparable operative time, complications, and outcomes.

Keywords: Inguinal; Huge; Double; Single; Mesh.

This is an open-access article registered under the Creative Commons, ShareAlike 4.0 International license [CC BY-SA 4.0] [https://creativecommons.org/licenses/by-sa/4.0/legalcode. 3 (3) July-September: 1589- 1597 [DOI: 10.21608/IJMA.2021.56574.1239].

${ }^{*}$ Main subject and any subcategories have been classified according to the research topic. 


\section{INTRODUCTION}

Hernia is a protrusion of the viscus or part of it within a peritoneal sac through the abdominal wall's defect. There are many types of hernia. The commonest one is the inguinal type, a protrusion of a viscus or a portion of it through the inguinal canal [1].

Many factors increase the risk of the inguinal hernia development: smoking, chronic obstructive pulmonary disease [COPD], increased body mass index [BMl], gestation, dialysis, connective tissue diseases, and previous open appendectomy [2].

Inguinal hernia may be direct, indirect, dual, or sliding. Indirect Inguinal hernia $[\mathrm{IIH}]$ is the commonest of inguinal hernias [65\%]. It occurs at any age but more common at a young age. Male to female ratio [20:1] due to the weakness of the wall by the spermatic cord. Direct Inguinal hernia is common in old-aged males [in practice, females never develop direct hernia]. It may arise at a young age following appendectomy due to the ilioinguinal nerve's injury supplying the conjoint tendon ${ }^{[3]}$.

Double hernia [pantaloon hernia. Saddlebag] in which both direct and $\mathrm{IIH}$ arising at the same side with the inferior epigastric vessels between the necks of the two sacs. Sliding hernia [organ forming part of the sac] occurs in a patient with a long-standing hernia. The peritoneum of the viscus forms a part of the sac, which may be the cecum, pelvic colon, urinary bladder ${ }^{[4]}$.

Sometimes, we consider hernia as a serious problem due to complications, including irreducibility, inflammation, and strangulation. Irreducibility is the failure of all contents or part of it to return to the abdomen. The commonest cause of irreducibility is adhesion between the sac and the contents or adhesions between the contents. Other causes are the narrow neck and overcrowding of the content. Irreducibility is the occlusion of the intestinal lumen, usually in an irreducible hernia, with no blood supply interference ${ }^{[5]}$. Inflammation either of the sac due to truss or to content [appendicitis, Mickel diverticulitis]. Strangulation is the most serious complication. There is interference with the blood supply of the contents with impending gangrene may occur within 4-6 hrs. It occurs mainly due to the sharp edge of the defect, narrow neck, and large contents. Usually, irreducibility and inflammation predispose for strangulation [1].

Symptoms of inguinal hernia are reported in $66 \%$ of affected populations. This may comprise pain or discomfort. These symptoms are marked with bowel movement, coughing, and exercise. Often it becomes worse during the day and recovers in recumbent position. There is a painless swelling in the inguinal region on local examination unless it is complicated as in obstruction. There will be repeated vomiting, absolute constipation, abdominal distention, and tender abdomen, while in a strangulated inguinal hernia, there will be colicky stabbing pain due to ischemia, which disappears if perforation occurs ${ }^{[6]}$.

A huge inguinal hernia surgical treatment is more often and markedly challenging. It is termed as a hernia that spreads below the inner mid-thigh when the subject is in standing ${ }^{[7]}$.

Regarding the treatment of inguinal hernia, the classic method of treating inguinal hernia is tension-free single mesh repair, which remains popular among today's surgeons. This is done either open or laparoscopic hernioplasty ${ }^{[8]}$. However, the recurrence rate of inguinal hernia is increasing and may be recurrent to the fourth or the fifth time. So, there must be a solution to decrease the rate of recurrence. One recent solution is to use a double mesh rather than a single mesh in hernioplasty ${ }^{[9]}$.

In these operations, we do both Onlay mesh placement in front of fascia transeversalis. Along with Inlay mesh placement in front of the peritoneum. Thus, the posterior wall of the inguinal canal becomes supported [10].

\section{AIM OF THE WORK}

The current study aimed to compare between single mesh and double mesh placement in huge inguinal hernia.

\section{PATIENTS AND METHODS}

This prospective interventional study was carried out in the General Surgery Department, Faculty of Medicine, AlAzhar University, and Damietta general hospital for two years, starting from June 2018 till June 2020. Fourty cases were involved in the study, categorized into two groups by alternative random selection method where each technique was applied separately on one of them. Candidates for the study were examined and investigated thoroughly regarding their complaint, the presence of clinically detectable hernia [lump] in the inguinal region, typically appears on standing and disappears on lying down, its size [huge size], characters, time onset, duration and associated symptoms like pain, colic, constipation, etc. A huge hernia was recognized as any hernia that extends below the mid-point of the inner thigh, in a standing position ${ }^{[11]}$.

The clinical examination included a general examination for hemodynamic vital signs and other systems to evaluate patient fitness to surgery and anesthesia. Local examination [abdominal examination] was done 
concentrating on the hernia site, size of the defects, reducibility, and any other signs of complications [e.g., infection, obstruction, strangulation]. The abdomen is also examined for any organomegaly or other intra-abdominal co-pathology to deal with it during hernia repair. Only patients with clinically detectable, symptomatic, and noncomplicated huge inguinal hernia were included in the study. Thus, inclusion criteria were: males with age $\geq 20$ years, with a primary, uncomplicated huge inguinal and/or bilateral hernia. However, only one side was attacked at a time. On the other side, exclusion criteria were: patients $<20$ years, patients with complications [obstruction, strangulation, or ulceration], surgical contraindications [peritonitis, infection at the site of operation...], small inguinal hernia, and patients unfit for surgery.

Ethical consideration: The participants who agree to share in this study sign a written consent after full information about the maneuver and its circumstances, were explained. The study was conducted after approval of the committee of ethics in, Faculty of Medicine EL-Azhar University [IRB number: IRB 00012367-18-05-002].

Methods: The patients were randomly divided into two groups according to the mesh position used to treat the uncomplicated huge inguinal hernia. Patients were admitted the day before surgery. The night before surgery, the operation site's preparation was done with hair shaving just before the operation in the morning. A single dose of broadspectrum antibiotic [third-generation cephalosporin] was given before anesthesia. General anesthesia with endotracheal intubation or spinal anesthesia was used. All patients were placed in the supine position. The skin was prepared by povidone-iodine and the operative field toweled up in a normal manner.

Group A [single mesh placement]: Twenty patients were operated on by placing the mesh over fascia tranversalis only. Horizontal $2-3 \mathrm{~cm}$ incision above and parallel to the inguinal ligament was created. The incision's most lateral point is that laying two fingerbreadths below and medial to the anterior superior iliac spine. Then, the incision advanced medially for 8 to $10 \mathrm{~cm}$ [Figure 1].

Electrocautery was used to split the subcutaneous tissues. Scarpa's fascia was recognized and divided to expose the aponeurosis of the external oblique muscle. An encountered vertical vein was ligated and divided between hemostat clamps. The external oblique aponeurosis was sharply divided parallel to the aponeurosis fibres direction.

Scissors were then advanced immediately below fibers, laterally at first and then medially toward the external inguinal ring, and spread as they are retracted to create a space and avoiding dissection of the ilioinguinal nerve [Figure 2]. The scissors were then used to incise the aponeurosis, split the external inguinal ring, and expose the inguinal canal and its contents.

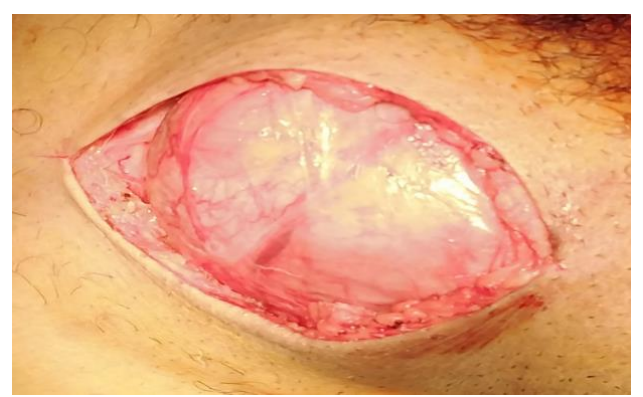

Figure [1]: The inguinal incision

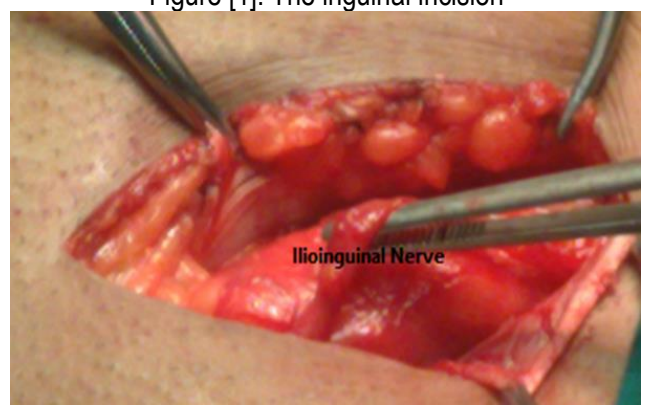

Figure [2]: Identification of the ilioinguinal nerve

Hemostat clamps were then applied to the aponeurosis superior and inferior edges and aponeurosis was then elevated from the inguinal canal. Blunt dissection was done to separate superior flap of the aponeurosis from the internal oblique muscle. The inferior flap was bluntly dissected to expose the shelving edge of the inguinal ligament. The iliohypogastric and ilioinguinal nerves were recognized and retracted away from the field. The pubic tubercle was recognized, and the cord restricted by the surgeon's index finger and the thumb as it passes the tubercle. A Penrose drain was positioned around the spermatic cord and its contents to allow its elevation from the floor of the inguinal canal.

With elevated cord, cremasteric fibers were visualized, and were divided bluntly to initiate the cord's skeletonization. Once the cremasteric fibers were divided completely between the external and internal inguinal rings, the inguinal canal floor was assessed for direct hernias and weak fascia. Care was exerted to prevent injury to the cord structures during the division of the cremasteric muscle [Figure 3].

Even in tension-free repairs, the inguinal canal floor was plicated with stitches to decrease the direct hernia sac when present. An indirect hernial sac was generally found on the antero-lateral surface of the spermatic cord. In addition to sac recognition, the vas deferens and spermatic cord vessels were identified to permit sac dissection from the 
cord. At the sac's fundus, the two peritoneum layers were folded upon themselves and a white edge was revealed, which may help recognition of the sac, and dissection was completed proximally toward the deep inguinal ring. The sac was opened and examined for any visceral contents, and the sac was excised after neck transfixation at the level of the internal ring [Figure 4].
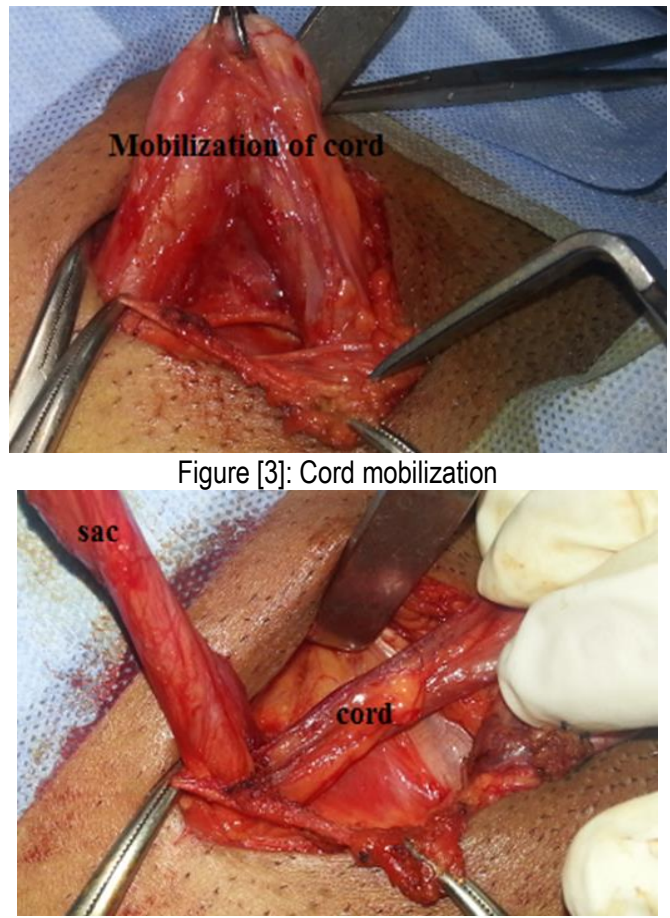

Figure [4]: Dissection of the hernial sac from other cord contents

The large hernia sac was divided by electrocautery. If the sac was wide, it was easier to displace it into the peritoneal cavity rather than its ligation. A sliding hernia grants a special challenge in hernia sac handling. A portion of the sac was composed of visceral peritoneum covering part of a retroperitoneal organ, usually the colon or bladder. In this situation, the grossly redundant part of the sac was excised, and the peritoneum reclosed. The organ and sac were reduced below the fascia transeversalis, as in a direct hernia [Figure 5].

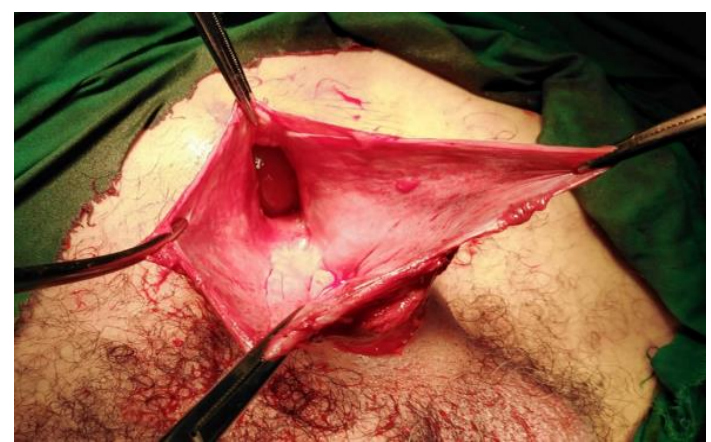

Figure [5]: Herniotomy with inspection of its contents The inguinal canal's posterior wall was visualized [fascia tranversalis]; simple interrupted sutures repair fascia tranversalis with polypropylene 0 . Then insertions of single Onlay mesh on the posterior wall, which was fixed by simple interrupted sutures with polypropylene 2-0 to pubic tubercle medially, conjoint tendon above, and inguinal ligament below. A suction drain was left in front of the mesh, and the spermatic cord layers were closed layer by layer with fine sutures [Figure 6].

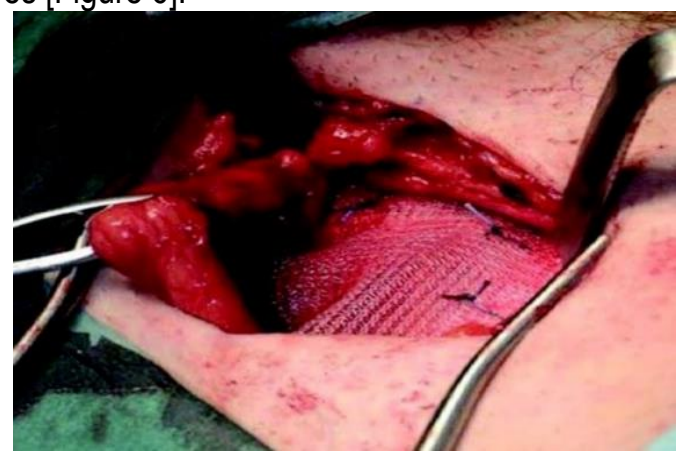

Figure [6]: Single mesh placement

Once the inguinal canal reconstruction was complete, the cord contents were returned to their anatomic position. The external oblique aponeuroses were then reapproximated by continuous stitches using vicryl 210 . Scarpa's fascia was closed with a series of interrupted sutures with vicryl 210. Lastly, the skin was closed with subcuticular stitches or simple interrupted stitches with polypropylene 3-0 [Figures 7, 8].
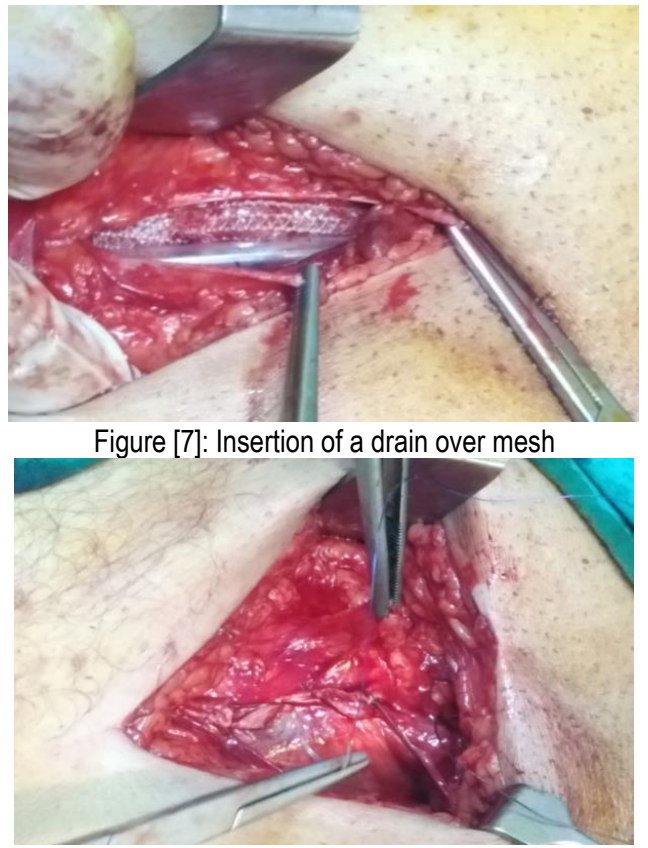

Figure [8]: Closure of Scarpa's fascia.

In group B [double mesh placement], twenty patients were operated on by placing the mesh in the preperitoneal space. The incision, mobilization of cord structures, and identification with reducing the sac and herniotomy were 
made in the first group.

Repair: The Initial steps are the same as the single mesh placement until the hernia sac was dealt with. Then the posterior wall of the inguinal canal is visualized [fascia tranversalis] very week. Two Hemostat clamps are then applied to fascia transeversalis to open the fascia in between the clamps by scissor. Scissor is then advanced laterally and then medially to reach the periperitoneal space, identifying the anterior peritoneum and ensuring it was intact.

Sublay mesh placement [Figure 9]: Insertion of a periperitoneal [sublay] mesh fixed to the bottom of conjoint tendon, rectus muscle and bottom of inguinal ligament by simple interrupted sutures with polypropylene 2-0. Repair of fascia transeversalis by simple interrupted sutures with polypropylene 2-0

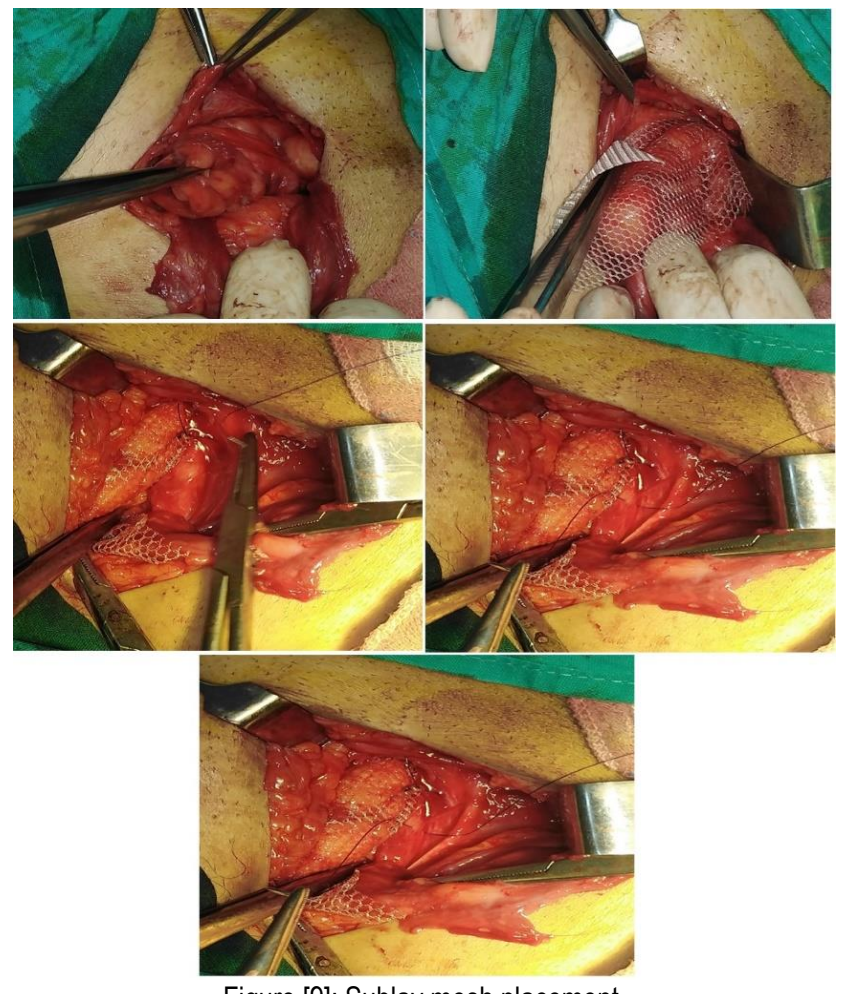

Figure [9]: Sublay mesh placement.

Onlay mesh placement [Figure 10]: Insertions of Onlay mesh on the posterior wall, which is fixed by simple interrupted sutures to pubic tubercle medially, conjoint tendon above, and inguinal ligament below with polypropylene 2-0. A suction drain is left in front of the mesh. The spermatic cord layers are closed with fine sutures. The inguinal canal is then closed by suturing the two flaps of the external oblique aponeurosis by continuous stitches with vicryl 210 . Finally, the wound was closed as in group A.

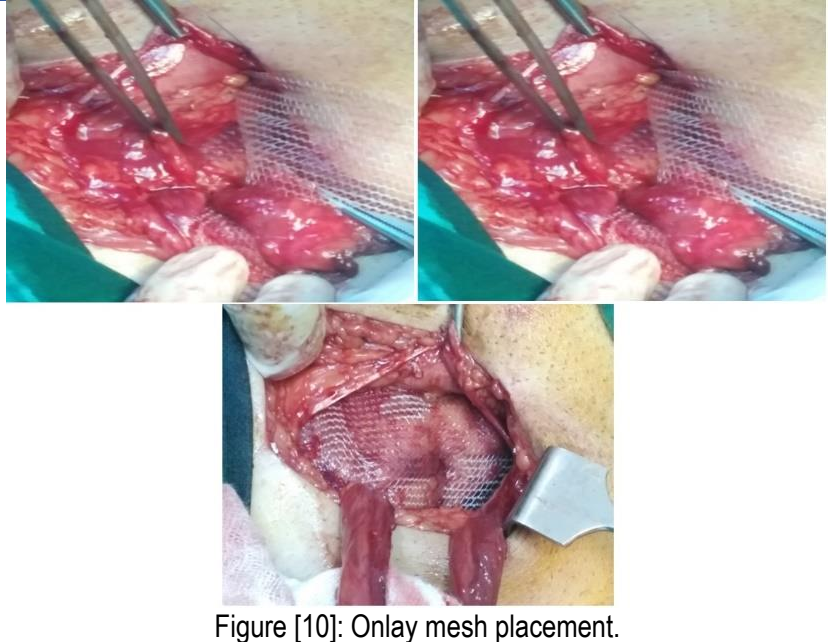

\section{Follow-up}

Inpatients are examined at discharge and seen at follow-up arranged visits at 7, 30 days, and 6, and 12 months after the surgery. Any recurrence or complications, return to normal activity, disfigurement, and scars were documented. Complications included seroma, wound infection, scrotal edema, chronic pain, and sensory changes. The return to activity was categorized into basic activity [ability to do basic activities [i.e., dressing, walking, bathing], home activity [traditional home activities [i.e., food preparation, and house cleaning]], and work activity [returning to all previous activities related to the work].

Beneficiaries: All patients involved in this study had direct benefits from the operation in repairing their hernias.

Statistical analysis: Statistical Package for the Social Sciences software was used. Normal distribution was checked by Shapiro-Wilk test. Quantitative [numerical] data was presented as mean and standard deviation, while qualitative variables were presented in frequency and percentage. Independent sample t and Mann Whitney tests were used for inter-group comparison of parametric and non-parametric continuous, respectively. Fisher exact and Chi-square tests were used for inter-group comparison of qualitative data. $P$ value $<0.05$ was recognized as the margin of significance.

\section{RESULTS}

The mean ages were 56 and 56.9 years for groups $A$ and $B$, respectively. Additionally, the mean $B M l$ values were 29.14 and $27.84 \mathrm{~kg} / \mathrm{m}^{2}$ in the same group, respectively, with no significant difference between the two groups $[p=0.379$ and 0.116 , respectively]. Besides, there was no significant difference between groups $A$ and $B$ regarding risk factors, type of hernia, and side of hernia [Table 1]. 
Regarding operative data and outcome, there was a significant decrease in operative time in group $A$ when compared to group B [54.50 \pm 8.256 vs. $61.25 \pm 6.664$ minutes, respectively]. However, there was no significant difference between groups $A$ and $B$ regarding blood loss [ml] [45.25 \pm 16.818 vs. $53.50 \pm 7.964$, respectively, $p=0.058$ ] The hospital stay duration [hours] was shorter in group $B$ when compared to group A $[23.40 \pm 9.110$ vs. $28.20 \pm 11.200$ hours, respectively]. However, the difference was statistically nonsignificant. The overall rate of complications was lower in group B when compared to group $\mathrm{A}[30.0 \%$ vs. $50.0 \%$, respectively]. Complications in group A was in the form of seroma [10.0\%], wound infection [5.0\%], scrotal edema [25.0\%], and chronic pain [10.0\%]; while in group B, seroma was reported in $10.0 \%$, scrotal edema [5.0\%], chronic pain [15.0\%], but wound infection was not addressed in any patient. The duration to return to work was shorter in group $A$ than group $B[26.40 \pm 3.299$ vs. $28.65 \pm 5.019$ respectively, $p=0.102$ ]. Recurrence was confined to group $A$, and reported to three patients [15.0\%]. However, the difference was statistically nonsignificant [Table 2].

Table [1]: Patient's demographics, risk factors, type and side of hernia in the study groups.

\begin{tabular}{|l|l|c|c|c|}
\hline \multicolumn{2}{|l|}{} & Group A [n= 20] & Group B [n= 20] & p \\
\hline Age [years] & $56.00 \pm 3.713$ & $56.90 \pm 2.573$ & 0.379 \\
\hline BMI [kg/m²] & $29.14 \pm 2.740$ & $27.84 \pm 2.313$ & 0.116 \\
\hline \multirow{2}{*}{$\begin{array}{l}\text { Risk } \\
\text { factors }\end{array}$} & History of smoking & $8[40.0 \%]$ & $6[30.0 \%]$ & 0.507 \\
\cline { 2 - 5 } & History of DM & $5[25.0 \%]$ & $2[10.0 \%]$ & 0.407 \\
\cline { 2 - 5 } & Hypertension & $8[40.0 \%]$ & $6[30.0 \%]$ & \multirow{3}{*}{0.598} \\
\hline \multirow{2}{*}{$\begin{array}{l}\text { Type of } \\
\text { hernia }\end{array}$} & Direct & $1[5.0 \%]$ & $0[0.0 \%]$ & \multirow{2}{*}{0.507} \\
\cline { 2 - 5 } & Indirect & $18[90.0 \%]$ & $19[95.0 \%]$ & \\
\cline { 2 - 5 } & Combined & $1[5.0 \%]$ & $1[5.0 \%]$ & \\
\hline \multirow{2}{*}{$\begin{array}{l}\text { Side of } \\
\text { hernia }\end{array}$} & Right & $12[60.0 \%]$ & $14[70.0 \%]$ & \\
\cline { 2 - 5 } & Left & $8[40.0 \%]$ & $6[30.0 \%]$ & \\
\hline
\end{tabular}

Table [2]: Operative data and outcome in the study groups

\begin{tabular}{|c|c|c|c|c|}
\hline \multirow{2}{*}{\multicolumn{2}{|c|}{ Operative time [minutes] }} & Group A [n= 20] & Group B [n=20] & $p$ \\
\hline & & $54.50 \pm 8.256$ & $61.25 \pm 6.664$ & $0.007^{*}$ \\
\hline \multicolumn{2}{|c|}{ Blood loss [ml] } & $45.25 \pm 16.818$ & $53.50 \pm 7.964$ & 0.058 \\
\hline \multicolumn{2}{|c|}{ Hospital stay [hours] } & $28.20 \pm 11.200$ & $23.40 \pm 9.110$ & 0.145 \\
\hline \multirow[t]{5}{*}{ Complications } & Seroma & $2[10.0 \%]$ & $2[10.0 \%]$ & \multirow[t]{5}{*}{0.33} \\
\hline & Wound infection & $1[5.0 \%]$ & $0[0.0 \%]$ & \\
\hline & Scrotal edema & $5[25.0 \%]$ & $1[5.0 \%]$ & \\
\hline & Chronic pain & $2[10.0 \%]$ & $3[15.0 \%]$ & \\
\hline & None & $10[50.0 \%]$ & $14[70.0 \%]$ & \\
\hline \multicolumn{2}{|c|}{ Return to work [days] } & $26.40 \pm 3.299$ & $28.65 \pm 5.019$ & 0.102 \\
\hline \multicolumn{2}{|c|}{ Recurrence } & $3[15.0 \%]$ & $0[0.0 \%]$ & 0.231 \\
\hline
\end{tabular}

\section{DISCUSSION}

Neglect of an inguinal hernia is a common event in Egyptians. Patients could not realize the importance of surgical hernia repair as early as possible. This postponing of repair potentially increases the magnitude of complications. In addition, it poses and technical challenge over the surgeon ${ }^{[12]}$.

To the best of researcher's knowledge, there is a paucity of studies comparing these patient populations' techniques. This is considered one of the strengths of our study. Results revealed that patients were in their fifties with no significant difference between both groups. Staubitz et al. ${ }^{[13]}$ reported that giant inguinoscrotal hernias are often associated with neglect for many years, explaining our cases' older age. This indicates the prolonged chronicity of hernias that developed at a younger age and increased in size without seeking surgical advice due to poverty and ignorance.

All patients in the current study were males. Likewise, the study carried out by Maghsoudi and Paarvand [14] had $100 \%$ men in their study. Most of patients in their study had one or more risk factor for development of hernia, the commonest was smoking [76.6\%], obesity [10\%], chronic obstructive pulmonary disease [20\%], and benign prostatic hypertrophy [20\%], which increased the risk for developing a hernia. 
Patients in the current work were relatively overweight, with no significant difference between groups. Al-Shemy et al. [15] reported nonsignificant difference between groups regarding BMI, with comparable results between groups. The same authors reported comparable results regarding the incidence of smoking as in the current work. Sørensen [16] reported that smoking is one of the most significant modifiable risk factors to be addressed in patients scheduled for surgical hernia repair. Smoking is associated with a reduction in end-tissue oxygenation and aerobic metabolism. This leads to impaired healing of the tissues after surgery, both by decreasing the inflammatory healing response and impaired proliferative response. Burcharth et al. [17] reported that smoking has also been directly associated with the high recurrence rates of inguinal hernia.

Diabetes mellitus reported in about $17 \%$ [ $25 \%$ in the first and $10 \%$ in the second group] with no significant difference between groups. Diabetes is considered a risk factor for impaired wound healing, with consequent high perioperative morbidity related to different surgeries. This was evident after cardiothoracic surgery, where there was a significant rise of wound complications in patient with perioperative poor-control of blood sugar ${ }^{[18]}$. Furthermore, base-line poor control diabetics [hemoglobin $\mathrm{A} 1 \mathrm{C}>8$ ] had doubled rate of superficial wound infection [19]. Diabetics also have a higher recurrence risk. Short-term complications after repair of inguinal hernia, including bleeding, infection, and wound dehiscence, are increased in diabetics than non-diabetics [20]. In our study, we did not electively repair inguinal hernias unless hemoglobin $\mathrm{A} 1 \mathrm{C}$ was $<8.0 \%$

IIHs are the most common type of groin hernia. If large enough, it emerges through the external ring and descends into the scrotum. Also, it is uncommon for direct hernias to reach the scrotum [2]. This confirms our findings regarding the type of hernias encountered.

Additionally, Nagaty [10] reported that operative time had mean values of 72.56 and 64.37 minutes in the double and single mesh groups, respectively. Like our study, operative time was significantly prolonged in the double mesh group $[p<0.01]$. Furthermore, Osman et al. ${ }^{[21]}$ also reported that the double mesh technique was associated with prolonged operative time compared to the standard single mesh procedure [1.93 vs. 1.33 hours, $p<0.001]$. The previous study was conducted on cases with lumbar rather than an inguinal hernia. However, it confirms that a significant extra time was needed for the insertion and fixation of the extra mesh in the double approach.

Intraoperative blood loss in the current work is comparable to the study conducted by Nagaty [10], who reported no significant difference between the two approaches regarding intraoperative bleeding incidence.

Like the current study, Al-Shemy and his associates [15] also reported that the median period of hospitalization ranged between 1 and 1.5 days, which agrees with our findings.

When it comes to the complications encountered in the current work, the most common were seroma, wound infection, scrotal edema, and chronic pain. The overall complications' rate was higher in group $A$, with no significant difference between groups. The recurrence was lower in the double mesh group, but the difference is statistically nonsignificant. Complications rate is comparable to previous literature [22-23]. Seromas are a known complication after laparoscopic or open repairs of hernia, especially in the scrotal hernia or after repair of large direct preperitoneal defects without plication of the fascia transeversalis. The incidence was between $0.5 \%$ and $12 \%$ [24].

In contrast with our findings, Ohana et al. ${ }^{[2]}$ seroma was more encountered in the single mesh group [33.33 vs. $15.62 \%$ in the double mesh group, $p<0.05]$.

In the current study, superficial surgical site infection occurred only in one case [5\%] in the single mesh group. Infection is always a concern after repairs of inguinal hernia, particularly with prosthetic material implantation [24]. Another study also negated any significant difference between the two approaches as regard wound infection [21].

Farouk et al. [26] reported that scrotal edema was encountered in $25 \%$ of the included cases, which comes in line with our findings. Another study reported that scrotal swelling occurred in about $10-15 \%$ of cases undergoing hernia repair ${ }^{[15] .}$

The incidence of chronic pain after repair of inguinal hernia ranges from $0.7 \%$ to $75 \%$ in the existing literature, depending on the definition used for chronic pain and study design ${ }^{[27]}$. We reported incidence rates in both groups within the previous range. In other study, long-term follow-up revealed that, $28.7 \%$ of cases reported some inguinal pain one year after surgery, with $11 \%$ of impairment of work- or daily-related activities, and $4.5 \%$ receiving analgesics [28]. After 6 years of follow up, $16.7 \%$ had the same pain and, $7.5 \%$ reported higher pain ${ }^{[29]}$.

Generally, no significant difference was perceived between the two techniques regarding any of the studied complications. Other authors reported that a double mesh repair was successful for complex and recurrent hernias. The complication rate was acceptable, with only two 
recurrences after a long term, follow up by a mean of 142 months ${ }^{[30]}$. Al-Shemy et al. [15] reported a much shorter duration than the current study required for return to work, which had mean values of 16 and 20 days in the study groups. The longer duration in our study could be explained by the fact that all of the included cases had huge hernias that might require prolonged postoperative home rest compared to small, simple hernias.

In our study, although recurrence was encountered in 3 cases [15\%] in the single mesh group versus no cases in the double mesh group, the difference was statistically insignificant. After inguinal hernia repair, recurrence rates have been reported to be less than $1 \%$ to $15 \%$ [31-32].

The second mesh use in laparoscopic repair to guard against recurrence, as advised here, is not unique. Felix and colleagues [33] proposed that a slit to house the vas deference and spermatic vessels was required, as they tend to raise the mesh off the inguinal floor. To avoid potential recurrence at the slit, they pronounced two mesh pieces' routine use in their approach to repair inguinal hernias. Posta [34] also described a double-mesh laparoscopic technique where two meshes were introduced in the preperitoneal space to prevent stapling to crucial areas [inferior epigastric vessels and lateral femoral cutaneous nerve] and to offer a more security to the inguinal floor. Halkic et al. ${ }^{[35]}$ suggested a simple adjustment of the double-mesh procedure to ensure more simplicity.

In line with current results, Nagaty [10] reported no significant differences between the postoperative recurrence rate approaches. One-year-follow up revealed recurrence in only $5 \%$ of the double mesh groups versus no single mesh group cases. However, the previous study was conducted on cases without giant hernias, and they were performed laparoscopy. These differences must be kept into consideration when comparing both studies. However, Glavan and his associates [36] reported the double mesh technique's superiority in preventing recurrence as that there were no recurrences in the double mesh group, with longer follow-up [range, 7 - 97 months]. In contrast, 1.0\% of patients treated with the standard one-mesh technique developed recurrences. A previous Egyptian study applied the same approaches in cases with lumbar hernias. Authors reported that the double mesh group had a significant decrease in postoperative recurrence rate $[40 \mathrm{vs.} 10 \%$ in the single and double mesh groups, respectively $-p=0.02]$ [21]. Also, Saad et al. [37] reported that the double-mesh reinforcement technique is associated with a lower recurrence rate. Furthermore, the repair of a large, complex hernia by double-mesh repair method was augmented by polypropylene Onlay mesh and results in reduction of the recurrence rates than reports of component separation procedure alone. Another case report also reported double mesh repair's effectiveness for a 77 -year-old patient with a huge inguinoscrotal hernia for $>50$ years. Patient recovery was uneventful, and he was discharged on the tenth postoperative day [38].

Our study has some limitations; it is a single-center study. The included sample size was relatively small. Besides, the study lacked intermediate, and long-term follow up. Hence more studies should be conducted to cover these perspectives.

Our findings show that the double mesh technique is a safe and efficacious approach for managing huge inguinal hernia. It is associated with lower recurrence rates than the single mesh approach with comparable operative time, complications, and outcomes.

\section{Financial and Non-financial Relationships and Activities of Interest}

None to be declared

\section{REFERENCES}

1. Köckerling F, Simons MP. Current Concepts of Inguinal Hernia Repair. Visc Med. 2018 Apr;34[2]:145-150. [DOI: 10.1159/000487278].

2. Perez AJ, Strassle PD, Sadava EE, Gaber C, Schlottmann F. Nationwide Analysis of Inpatient Laparoscopic Versus Open Inguinal Hernia Repair. J Laparoendosc Adv Surg Tech A. 2020 Mar;30 [3]: 292-298. [DOI: 10.1089/lap.2019.0656].

3. Kabir AA, Bahar MAA, Haque MF, Farooqui MO, Babul M, Akter MS, et al. Evaluation of clinico-epidemiological profile and associated risk factors of inguinal hernia. A Prospective observational study. Int $\mathrm{J}$ Surg Sci. 2020; 4[3]: 31-36. [DOI: 10.33545/ surgery. 2020. v4.i3a.467].

4. Kadiyal AM, Gowtham T, Ghatage MN, Singh RK, Thimmegowda, V. Pantaloon hernia with two sliding components: The appendixascending colon in lateral sac and the urinary bladder in medial sac. Formosan J Surg. 2020; 53[4]: 148 . [DOI: 10.4103/fjs.fjs_95_19].

5. Weyhe D, Tabriz N, Sahlmann B, Uslar VN. Risk factors for perioperative complications in inguinal hernia repair - a systematic review. Innov Surg Sci. 2017 Feb 25; 2[2]:47-52. [DOI: 10.1515/iss2017-0008].

6. Hammoud M, Gerken J. Inguinal Hernia. 2020 Sep 8. In: StatPearls [Internet]. Treasure Island [FL]: StatPearls Publishing; 2020 Jan. [PMID: 30020704]. Available at https://www.ncbi.nlm.nih.gov/ books/ NBK513332/.

7. Anand M, Hajong R, Naku N, Hajong D, Singh KL. Giant Inguinal Herniae Managed by Primary Repair: A Case Series. J Clin Diagn Res. 2017 Feb;11[2]:PR01-PR02. [DOI: 10.7860/JCDR/2017/22916. 9180].

8. Ramji AN. Repair of the Giant Inguinal Hernia: more than mere reduction and reinforcement. Int J Surg Sci. 2019; 3: 28-30. [DOI: 10.33545/surgery. 2019. v3.i2a.09]

9. Caprino P, Sacchetti F, Schena CA, Sofo L. Total Colon "Collapse" in Giant Left-Sided Inguino-Scrotal Hernia: Double-Mesh Plastic 
Repair. Indian J Surg. 2020; 82[3]: 427-429. [DOI: 10.1007/s12262019-01962-9]

10. Nagaty ME. Laparoscopic Repair of Bilateral Inguinal Hernia Using Large Butterfly Mesh Without Fixation Versus Double Meshes with Stapler Fixation through TAPP Approach. Egy J Hosp Med. 2019; 75[3]: 2374-2380. [DOI: 10.12816/ ejhm. 2019. 30758]

11. Trakarnsagna A, Chinswangwatanakul V, Methasate A, Swangsri J, Phalanusitthepha C, Parakonthun T, Taweerutchana V, Akaraviputh T. Giant inguinal hernia: Report of a case and reviews of surgical techniques. Int J Surg Case Rep. 2014;5[11]:868-72. [DOI: 10.1016/ j.jjscr.2014.10.042].

12. El-Komy H, El-Gendi A, Abdel-Salam W, Elseidy M, Elkayal E. Selffixing parietex progrip versus the standard sutured prolene mesh in tension-free repair of inguinal hernia: effect on testicular volume and testicular blood flow. Updates Surg. 2018 Dec; 70 [4]: 513-520. [DOI: 10.1007/s13304-018-0554-0].

13. Staubitz JI, Gassmann P, Kauff DW, Lang H. Surgical treatment strategies for giant inguinoscrotal hernia - a case report with review of the literature. BMC Surg. 2017 Dec 19; 17[1]: 135. [DOI: 10.1186/s12893-017-0331-x].

14. Maghsoudi H, Pourzand A. Giant prosthetic reinforcement of the visceral sac: the Stoppa groin hernia repair in 234 patients. Ann Saudi Med. 2005 May-Jun;25[3]:228-32. [DOI: 10.5144/0256-4947. 2005.228].

15. Al-Shemy G, Hassan A, Elias AAK, Nagi A. Evaluation of open hernioplasty in bilateral inguinal hernia repair. AZMJ 2018; 16[1]: 6672. [DOI: 10.4103/AZMJ. AZMJ_34_18].

16. Sørensen LT. Wound healing and infection in surgery: the pathophysiological impact of smoking, smoking cessation, and nicotine replacement therapy: a systematic review. Ann Surg. 2012 Jun;255[6]:1069-79. [DOI: 10.1097/SLA.0b013e31824f632d].

17. Burcharth J, Pommergaard HC, Bisgaard T, Rosenberg J. Patientrelated risk factors for recurrence after inguinal hernia repair: a systematic review and meta-analysis of observational studies. Surg Innov. 2015 Jun;22[3]:303-17. [DOI: 10.1177/ 1553350614552731].

18. Latham R, Lancaster AD, Covington JF, Pirolo JS, Thomas CS Jr. The association of diabetes and glucose control with surgical-site infections among cardiothoracic surgery patients. Infect Control Hosp Epidemiol. 2001 Oct;22[10]:607-12. [DOI: 10.1086/501830].

19. Shada A. Preoperative Considerations and Patient Optimization. In LaPinska, M. P. and Blatnik, J. A. [Eds.], Surgical Principles in Inguinal Hernia Repair : A Comprehensive Guide to Anatomy and Operative Techniques; Cham: Springer International Publishing 2018; pp. 3-6

20. Hellspong G, Gunnarsson U, Dahlstrand U, Sandblom G. Diabetes as a risk factor in patients undergoing groin hernia surgery. Langenbecks Arch Surg. 2017 Mar; 402 [2]: 219-225. [DOI: 10.1007/ s00423-016-1519-8].

21. Osman G, Habib FM, Sallam AM, Gertallah LM. Double mesh technique [mesh plug and onlay] in repair of lumbar incisional hernia: a novel technique. Egy J Surg. 2018; 37[4]: 562-568. [DOI: 10.4103/ ejs.ejs_87_18].

22. Bansal VK, Misra MC, Babu D, Victor J, Kumar S, Sagar R, Rajeshwari S, Krishna A, Rewari V. A prospective, randomized comparison of long-term outcomes: chronic groin pain and quality of life following totally extraperitoneal [TEP] and transabdominal preperitoneal [TAPP] laparoscopic inguinal hernia repair. Surg Endosc. 2013;27[7]:2373-82. [DOI: 10.1007/s00464-013-2797-7].

23. Oguz $H$, Karagulle $E$, Turk E, Moray $G$. Comparison of peritoneal closure techniques in laparoscopic transabdominal preperitoneal inguinal hernia repair: a prospective randomized study. Hernia. 2015 Dec;19[6]:879-85. [DOI: 10.1007/s10029-015-1431-0].

24. Nguyen DK, Chen DC. Results and Complications of Inguinal Hernia Repair. In Campanelli, G. [Ed.], The Art of Hernia Surgery: A Stepby-Step Guide. Cham: Springer International Publishing 2018; pp. 381-396

25. Ohana G, Powsner E, Melki Y, Estlein D, Seror D, Dreznik Z. Simultaneous repair of bilateral inguinal hernias: a prospective, randomized study of single versus double mesh laparoscopic totally extraperitoneal repair. Surg Laparosc Endosc Percutan Tech. 2006 Feb;16[1]:12-7. [DOI: 10.1097/01.sle.0000202195.51699.63].

26. Farouk A, Selimah MA, El-Fakharany M. Safety and stability of inguinal hernia repair in Egyptian patients suffering from portal hypertension-associated ascites using ultrasound-guided nerve block. Egy J Surg. 2017; 36[2]: 156-161. [DOI: 10.4103/11101121.204530].

27. Alfieri S, Amid PK, Campanelli G, Izard G, Kehlet H, Wijsmuller AR, Di Miceli D, Doglietto GB. International guidelines for prevention and management of postoperative chronic pain following inguinal hernia surgery. Hernia. 2011 Jun;15[3]:239-49. [DOI: 10.1007/s10029-0110798-9].

28. Bay-Nielsen M, Perkins FM, Kehlet H; Danish Hernia Database. Pain and functional impairment 1 year after inguinal herniorrhaphy: a nationwide questionnaire study. Ann Surg. 2001 Jan;233[1]:1-7. [DOI: 10.1097/00000658-200101000-00001].

29. Aasvang EK, Bay-Nielsen M, Kehlet $H$. Pain and functional impairment 6 years after inguinal herniorrhaphy. Hernia. 2006 Aug;10[4]:316-21. [DOI: 10.1007/s10029-006-0098-y].

30. Afifi RY, Hamood M, Hassan M. The outcome of A. Double mesh intraperitoneal repair for complex ventral hernia: A retrospective cohort study. Int J Surg. 2018 May;53:129-136. [DOI: 10.1016/ j.jju.2018.03.036].

31. Karthikesalingam A, Markar SR, Holt PJ, Praseedom RK. Metaanalysis of randomized controlled trials comparing laparoscopic with open mesh repair of recurrent inguinal hernia. Br J Surg. 2010 Jan; 97[1]:4-11. [DOI: 10.1002/bjs.6902].

32. Cavazzola LT, Rosen MJ. Laparoscopic versus open inguinal hernia repair. Surg Clin North Am. 2013 Oct;93[5]:1269-79. [DOI: 10.1016/ j.suc.2013.06.013].

33. Felix EL, Michas CA, Gonzalez MH Jr. Laparoscopic hernioplasty. TAPP vs TEP. Surg Endosc. 1995 Sep;9[9]:984-9. [DOI: 10.1007/ BF00188456].

34. Posta CG. Laparoscopic inguinal hernia repair with extraperitoneal double mesh technique. J Laparoendosc Adv Surg Tech A. 1997 Feb;7[1]:19-27. [DOI: 10.1089/lap.1997.7.19].

35. Halkic N, Ksontini R, Corpataux JM, Bekavac-Beslin M. Laparoscopic inguinal hernia repair with extraperitoneal double-mesh technique. $\mathrm{J}$ Laparoendosc Adv Surg Tech A. 1999 Dec;9[6]:491-4. [DOI: 10.1089/lap.1999.9.491].

36. Glavan E, Mijic A, Bekavac-Beslin M, Franjić DB, Jurisić D. Endoscopic extraperitoneal inguinal hernia repair with double mesh: indications, technique, complications, and results. J Laparoendosc Adv Surg Tech A. 2005 Dec;15[6]:586-90. [DOI: 10.1089/lap. 2005.15.586].

37. Saad HA, El Teliti AM, Fiad AA, Heggy IA. Double-mesh technique abdominal wall reconstruction for severe rectus diastasis and ventral hernia repairs [two for two]. Egy J Surg 2019; 38[2]: 221.

38. Sahsamanis G, Samaras S, Basios A, Katis K, Dimitrakopoulos G. Treatment of a half century year old giant inguinoscrotal hernia. A case report. Int J Surg Case Rep. 2016;25:51-4. [DOI: 10.1016/ j.jjscr.2016.05.039]. 

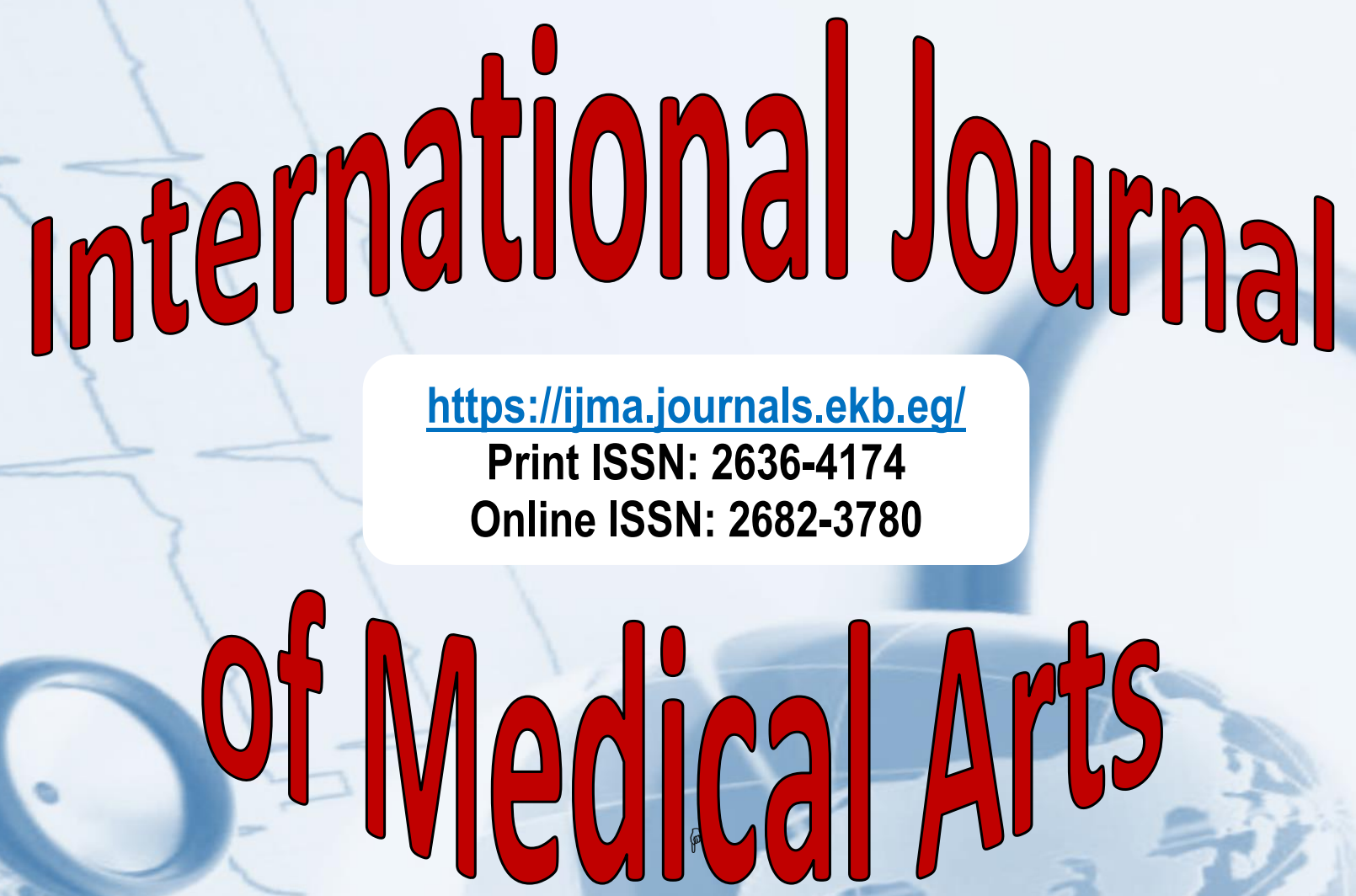